TITLE:

\title{
Metabolic engineering for the production of polyunsaturated fatty acids by oleaginous fungus Mortierella alpina 1S-4.
}

\section{AUTHOR(S):}

Sakuradani, Eiji; Ando, Akinori; Shimizu, Sakayu; Ogawa, Jun

\section{CITATION:}

Sakuradani, Eiji ...[et al]. Metabolic engineering for the production of polyunsaturated fatty acids by oleaginous fungus Mortierella alpina 1S-4.. Journal of bioscience and bioengineering 2013, 116(4): 417-422

\section{ISSUE DATE:}

2013-10

URL:

http://hdl.handle.net/2433/178746

\section{RIGHT:}

(C) 2013 The Society for Biotechnology, Japan. Published by Elsevier B.V.; This is not the published version. Please cite only the published version.; この論文は出版社版でありません。引用の際には出版社版を ご確認ご利用ください。 
1 Metabolic engineering for the production of polyunsaturated fatty acids by 2 oleaginous fungus Mortierella alpina 1S-4

3

4 Running Title: Microbial production of polyunsaturated fatty acids

5

6 Eiji Sakuradani, ${ }^{1,}{ }^{*}$ Akinori Ando, ${ }^{2}$ Sakayu Shimizu, ${ }^{3}$ Jun Ogawa ${ }^{1}$

7 Division of Applied Life Sciences, Graduate School of Agriculture, Kyoto University,

8 Sakyo-ku, Kyoto 606-8502, Japan ${ }^{1}$, Research Division of Microbial Sciences, Kyoto

9 University, Sakyo-ku, Kyoto 606-8502, $\mathrm{Japan}^{2}$, and Faculty of Bio-environmental

10 Science, Kyoto Gakuen University, Kameoka, Kyoto 621-8555, Japan ${ }^{3}$

11

12

* Corresponding author, Tel: +81 (0) 75753 6114; fax: +81 (0) 757536128 .

13 E-mail address: esakura@kais.kyoto-u.ac.jp (E. Sakuradani). 
1 Researches related with the application of functional lipids such as 2 polyunsaturated fatty acids (PUFAs) have been conducted in various fields with a 3 view to health and dietary requirements. Novel rich sources other than known 4 natural sources such as plant seeds and fish oils are required for increasing 5 demands of PUFAs. The filamentous fungus Mortierella alpina 1S-4 produces 6 triacylglycerols rich in arachidonic acid, i.e., ones reaching $20 \mathrm{~g} / \mathrm{l}$ in concentration 7 and containing $\mathbf{3 0 - 7 0 \%}$ arachidonic acid as total fatty acids. Various mutants 8 derived from $M$. alpina $1 \mathrm{~S}-4$ have led to the production of oils containing various

9 PUFAs. Molecular breeding of $M$. alpina strains by means of manipulation of the genes involved in PUFA biosynthesis facilitates improvement of PUFA productivity and elucidation of the functions of their enzymes. This review describes practical PUFA production through mutant breeding, functional analyses of the genes of the enzymes involved in PUFA biosynthesis, and recent advances in unique PUFA

14 production through molecular breeding.

[Key words: Mortierella alpina; Polyunsaturated fatty acid; Arachidonic acid (AA); 
Polyunsaturated fatty acids (PUFAs) contain more than one double bond, and some

20-carbon (C20) PUFAs play important roles not only as structural components of membrane phospholipids but also as precursors of eicosanoids, signaling molecules including prostaglandins, thromboxanes, and leukotrienes, that are essential for all mammals. Especially, arachidonic acid (AA; 20:4n-6), a representative n-6 PUFA, is

6 the most abundant C20 PUFA in humans, and not only exhibits various regulation

7 effects and physiological activities but also plays important roles in infant nutrition $(1,2)$.

8 Eicosapentaenoic acid (EPA; 20:5n-3), a representative n-3 PUFA, is beneficial in the

9 treatment of cardiovascular diseases (3), and decreases platelet aggregation and blood pressure (4). The distinct functions of the two families make the ratio in the diet of $n-6$ and n-3 PUFAs important in inflammatory responses and cardiovascular health. The most readily available lipid sources relatively rich in C20 PUFAs, none of which are found in plants, are fish oils, animal tissues, and algal cells. Transgenic plants with some exogenous desaturase genes have been reported to produce n-3 and n-6 PUFAs (5). However, these transgenic sources are unsuitable for practical purposes from the viewpoint of genetically modified organisms. The term "Single Cell Oils" is used for unique oils produced by microorganisms that compete with plant-seed oils and fish oils (6). Some yeasts and molds are known as microorganisms that accumulate high levels of triacylglycerols. A lipid content in excess of $40 \%(\mathrm{w} / \mathrm{w})$ is not exceptional, and values of $70 \%$ and even $80 \%$ have been reported (7). Single Cell Oils having different fatty acid compositions from plant-seed oils and fish oils are valuable for human life. able to produce EPA through the n-3 PUFA biosynthetic pathway, while AA through the 
n-6 PUFA biosynthetic pathway (8-10). In this strain, most PUFAs are present in triacylglycerols as storage oils, while some are present in phospholipids as structural components of membranes.

Although success in this area over the last 25 years has generated much interest in the development of microbial fermentation processes, manipulation of the lipid compositions of microorganisms requires new biotechnological strategies to obtain high yields of the desired PUFAs. This article reviews recent progress in the breeding of commercially important arachidonic acid-producing $M$. alpina strains, particularly approaches to creating desaturase and elongase mutants with unique pathways for PUFA biosynthesis involving conventional chemical mutagenesis and modern molecular genetics.

\section{VARIOUS KINDS OF PUFAs IN M. alpina 1S-4}

\section{Isolation of mutants producing PUFAs through different biosynthetic pathways}

Various mutants defective in desaturase $(\Delta 9, \Delta 12, \Delta 6, \Delta 5$ and $\omega 3)$ or elongase (MALCE1) activities, or with enhanced desaturase activities ( $\Delta 6$ and $\Delta 5$ ) have been derived from $M$. alpina $1 S-4$ by treating the parental spores with $N$-methyl- $N$ '-nitro- $N$-nitrosoguanidine

In addition, a diacylglycerol-accumulating mutant and several lipid-excretive ones have been obtained by the same method. They are valuable not only as producers of useful PUFAs (novel or already existing) but also for providing valuable information on PUFA biosynthesis in this fungus (12). The main features of these mutants are summarized in Table 1. 
1 (up to $40 \%$ ) in the mycelial oil (13). $\Delta 12$ Desaturase-defective mutants accumulate

2 high levels of n-9 PUFAs, such as Mead acid (MA; 20:3n-9) that are not detected in the

3 wild strain because of a complete deficiency of $\Delta 12$ desaturation (Fig. 1A). One of

4 these mutants, JT-180, yields a large amount of MA $(2.6 \mathrm{~g} / \mathrm{L}, 49 \%$ in oil $)$ on

5 commercial production due to its enhanced $\Delta 5$ and $\Delta 6$ desaturase activities, not

6 including n-6 and n-3 PUFAs (14). Double mutants defective in both $\Delta 12$ and $\Delta 5$

7 desaturase activities accumulate n-9 eicosadienoic acid (20:2n-9) as a final product of

$8 \mathrm{n}-9$ PUFAs in large quantities (15). $\Delta 6$ Desaturase-defective mutants accumulate

9 linoleic acid (18:2n-6) as the main fatty acid (up to 32\%) in the mycelial oil (16).

10 These mutants are characterized by the accumulation of n- 6 eicosadienoic acid

11 (20:2n-6) and nonmethylene-interrupted n-6 eicosatrienoic acid (20:3n-6 $\Delta 5)$

12 synthesized from linoleic acid, as shown in Fig. 1B. $\Delta 5$ Desaturase-defective mutants

13 exhibit a high dihomo- $\gamma$-linolenic acid (DGLA; 20:3n-6) level (4.1 g/L, 42\% in oil) and

14 a reduced concentration $(<1 \%)$ of AA (17). One of these mutants, S14, is used for the

15 commercial production of DGLA. $\omega 3$ Desaturase-defective mutants are unable to

16 synthesize n-3 PUFAs at temperatures below $20^{\circ} \mathrm{C}$ (18), although the wild strain

17 accumulates n-3 PUFAs such as EPA below that temperature. Therefore, these

$18 \omega 3$-desaturase defective mutants are superior to the wild strain for lipid production with

19 a relatively high content of AA. The fatty acid profile of elongase (EL1 for the

20 conversion of palmitic acid, 16:0, to 18:0)-defective mutants is characterized by high

21 levels of 16:0 and palmitoleic acid (16:1n-7), with small amounts of various kinds of

22 n-7 and n-4 PUFAs, as shown in Fig. 1c, which are not detected in the wild strain. The

23 total content of these PUFAs in the oil reaches about $30 \%$. In a similar manner, $\mathrm{n}-1$

24 PUFAs can be produced from n-1 hexadecenoic acid (16:1n-1) or 1-hexadecene added 
1 to the medium (see Fig. 1C). Triacylglycerols produced by M. alpina $1 \mathrm{~S}-4$ account for

$290 \%$ of the total lipids, whereas diacylglycerol-accumulating mutant KY1 derived from

3 the wild strain accumulates $30 \%$ diacylglycerols in the total lipids. Lipid-excretive

4 mutant V6 shows the same lipid productivity and fatty acid composition as the wild

5 strain, and excretes $10-40 \%$ of the total lipids into the medium during submerged

6 cultivation. Many lipid particles containing triacylglycerols are observed on the

7 surface of V6 mycelia cultivated on a solid medium. V6 is assumed to excrete

8 accumulated lipids out of its mycelia due to its insufficient cell wall structure caused by

9 mutations in the metabolic pathways for cell wall synthesis.

Characterization of enzyme genes involved in PUFA biosynthetic pathways The genes encoding the fatty acid desaturases and elongases involved in C20 PUFA biosynthesis in M. alpina $1 \mathrm{~S}-4$ and its mutant strains were characterized, as described below. These nucleotide sequence information revealed mutation sites of the enzymes in the representative mutants as described above (see Table 1).

16 The three $\Delta 9$ desaturase homologues (designated as $\Delta 9-1, \Delta 9-2$, and $\omega 9$ ) in M. alpina

17 1S-4 has a cytochrome $b_{5}$-like domain linked to its carboxyl terminus, as also seen for the yeast $\Delta 9$ desaturase (19). Mortierella $\Delta 9-1$ exhibits $45 \%$ and $34 \%$ amino acid sequence similarity with those of Saccharomyces cerevisiae and rat, suggesting that the Mortierella $\Delta 9-1$ is a membrane-bound protein using acyl-CoA as substrates. Both $\Delta 9-1$ and $\Delta 9-2$ desaturate $18: 0$ to oleic acid (18:1n-9), whereas $\omega 9$ desaturates a very long saturated fatty acid (26:0) to the corresponding monounsaturated fatty acid (26:1n-9) (20). Although the $49-2$ gene is not transcribed in the wild strain, the $\Delta 9-2$ gene is transcribed and its derivative enzyme exhibits $\Delta 9$ desaturation activities in $\Delta 9$ 
1 desaturation-defective mutants which have a mutation site in its $49-1$ gene.

2 Mortierella $\Delta 5$ and $\Delta 6$ desaturases have a cytochrome $b_{5}$-like domain linked to its

3 N-terminus. The two $\Delta 6$ desaturase homologues (designated as $\Delta 6-1$ and $\Delta 6-2$ ) are in

4 the wild strain, in which the $\Delta 6-1$ gene is transcribed much more highly (2- to 17 -fold)

5 than the $\Delta 6-2$ one (21). Mortierella $\Delta 12$ and $\omega 3$ genes lacking a region encoding a

6 cytochrome $b_{5}$-like domain were cloned and characterized by means of heterologous

7 gene expression systems. The gene expression analysis in yeast revealed that

8 Mortierella $\omega 3$ desaturase converts n-6 PUFAs to n-3 PUFAs with carbon 18 and 20

9 chain lengths, especially Mortierella $\omega 3$ desaturase could effectively convert AA into EPA (22).

M. alpina $1 \mathrm{~S}-4$ possesses 4 kinds of genes encoding fatty acid elongases (MALCE1, MALCE2, GLELO, and MAELO) involved in long chain saturated fatty acid or PUFA biosynthetic pathways. MALCE1 and MALCE2 belong to $\Delta 9$ elongases which efficiently perform elongation of 16:1n-7, 18:2n-6, and 18:3n-3. Furthermore, MALCE1 plays an important role in the elongation of 16:0 to 18:0 in M. alpina 1S-4 (23). GLELO is a $\Delta 6$ elongase which plays a critical role in the elongation of both C18 n-3 and C18 n-6 PUFAs to the corresponding C20 PUFAs (24). The enzyme encoded by the maelo gene was demonstrated to be involved in the biosynthesis of saturated fatty acids (20:0, 22:0, and24:0) in M. alpina 1S-4 (25).

GENETIC MANIPULATION OF M. alpina STRAINS FOR PUFA 
1 system for $M$. alpina $1 \mathrm{~S}-4$ has been developed with $M$. alpina uracil auxotrophs and a

2 complementary gene as selective marker (26). M. alpina uracil auxotrophs were

3 isolated by spontaneous mutation on a solid medium containing 5-fluoroorotic acid, of

4 which $0.5 \mathrm{mg} / \mathrm{ml}$ inhibited the growth of the wild strain completely, with the addition of

5 a little uracil. The uracil auxotrophs were proved each to have a point mutation in the

6 ura5 gene encoding orotidine-5'-monophospate decarboxylase. These uracil

7 auxotrophs, used in the transformation as hosts, were confirmed to exhibit the same

8 lipid productivity, AA productivity, growth speed, and spore formation capacity as the

9 wild strain.

10 Transformation with spores of $M$. alpina $1 \mathrm{~S}-4$ and a vector containing the M. alpina 1S-4 ura5 gene as a marker has been performed through microprojectile bombardment (27), while other methods frequently used for transformation, such as ones involving protoplasting, lithium acetate, and electroporation, did not give satisfactory results, because of the difficulty of effective protoplast formation by the use of general and commercial lytic enzymes, such as chitinase, chitosanase, and glucanase, for cell walls. Transformants were obtained at a transformation frequency of 0.4 transformants $/ \mu \mathrm{g}$ of vector DNA. Southern blot analysis revealed that most of the integrated plasmids in the stable transformants were present as several copies at ribosomal DNA (rDNA) positions and/or random positions in the chromosomal DNA.

An Agrobacterium tumefaciens-mediated transformation system for M. alpina 1S-4 has been developed (28), in which the ura5 gene is used as a selectable marker under the control of the homologous histone H4.1 promoter in the transfer-DNA region. The

23 frequency of transformation reached more than 400 transformants $/ 10^{8}$ spores.

24 Southern blot analysis revealed that most of the integrated transfer-DNA appeared as a 
single copy at a random position in the chromosomal DNA.

M. alpina 1S-4 exhibits resistance to various antibiotics used in the transformation systems of filamentous fungi. A high concentration $(20 \mathrm{mg} / \mathrm{ml})$ of Zeocin completely inhibited the germination of M. alpina $1 \mathrm{~S}-4$ spores, and decreased the rate of growth of fungal filaments to some extent. M. alpina 1S-4 showed Zeocin resistance with integration of the Zeocin-resistance gene at the rDNA locus of the genomic DNA (29). On the other hand, the fungicide carboxin $(100 \mu \mathrm{g} / \mathrm{ml})$ was found to inhibit the hyphal growth and spore germination of $M$. alpina $1 \mathrm{~S}-4$ completely (30). The $s d h B$ gene encodes the iron-sulfur (Ip) subunit of the succinate dehydrogenase (SDH, EC 1.3.99.1) complex. The mutated $s d h B(C B X B)$ gene, which leads to an amino acid substitution (H243L, a highly conserved histidine residue within the third cysteine-rich cluster of SDHB being replaced by a leucine residue), conferred carboxin resistance. The transformants obtained with the homologous $C B X B$ gene from $M$. alpina $1 \mathrm{~S}-4$ as a selective marker exhibited carboxin resistance. The $s d h C$ gene encoding a subunit of the SDH complex was also isolated from M. alpina $1 \mathrm{~S}-4$. The $s d h C$ gene has been reported to act as a selectable marker instead of the $s d h B$ gene (31). In the same manner, a mutated $s d h C(C B X C)$ gene was constructed to encode a modified SdhC with an amino acid substitution (H83K and T86I, highly conserved histidine and threonine residues within a putative SDH quinine-binding site of SDHC being replaced by lysine and isoleucine ones respectively). Transformants obtained with a $C B X C$ plasmid exhibited carboxin resistance, too. These genes for Zeocin and carboxin resistance are thus useful as selective markers in the transformation not only of the parental strain, $M$. alpina $1 \mathrm{~S}-4$, but also of its mutants. 
PUFA production through molecular breeding of $M$. alpina A practical

2 transformation system for M. alpina $1 \mathrm{~S}-4$ allows overexpression and RNA interference

3 (RNAi) of the genes involved in PUFA biosynthesis for improvement of the production

4 of various PUFAs. The valuable Mortierella mutants derived by chemical mutagenesis

5 were directly transformed with drug resistance markers, or their uracil auxotrophs were

6 transformed with the ura5 marker. Molecular breeding of M. alpina $1 S-4$ and its

7 mutants led to unique fatty acid profiles and high productivities of valuable PUFAs, as

8 summarized in Table 2.

9 Mutant JT-180 exhibits no activities of $\Delta 12$ desaturase and enhanced $\Delta 5$ and $\Delta 6$ desaturase activities. On overexpression of the endogenous $\Delta 12$ gene in JT-180, it accumulated a higher amount of AA $(2.0 \mathrm{~g} / 1 / 7 \mathrm{~d}, 39 \%$ of total fatty acids $)$, instead of MA, due to both enhanced $\Delta 5$ and $\Delta 6$ desaturation as compared to the case of the wild strain $(1.2 \mathrm{~g} / 1 / 7 \mathrm{~d}, 21 \%)$.

Expression of the gene encoding GLELO, which has been suggested to be the limiting step in AA biosynthesis (32), was successfully performed in M. alpina 1S-4 (33). The resulting transformants yielded more AA (3.6 g/l/10 days, 28\%) than the wild strain (1.9 g/l/10 days, 19\%). In addition, overexpression of the endogenous malcel gene in M. alpina $1 \mathrm{~S}-4$ also led to faster and higher AA accumulation (0.76 g/l/6 $\mathrm{d}, 34 \%)$ than in the wild strain $1 \mathrm{~S}-4(0.68 \mathrm{~g} / \mathrm{l} / 6 \mathrm{~d}, 28 \%)$. Overexpression of both malce 1 and glelo genes had significant effects on AA production by M. alpina 1 S-4.

21 The $\Delta 5$ and $\Delta 6(\operatorname{Pav} \Delta 5$ and Ost $\Delta 6)$ desaturases from microalgae Pavlova salina and of substrates. On the other hand, the $\Delta 5$ and $\Delta 6$ desaturases from $M$. alpina make

24 phospholipids their substrates. By gene expression of these microalgal desaturases 
1 with different substrate specificities for fatty acid derivatives in M. alpina, higher

2 contents of PUFAs might be obtained through molecular breeding. Overexpression of

3 the $\operatorname{Pav} \triangle 5$ gene in the wild strain led to a high rate of AA and a quite low rate of DGLA

4 in the total fatty acids, compared with AA and DGLA rates in the wild strain. As the

5 same manner, overexpression of the Ost $\Delta 6$ gene in the wild strain led to a total higher

6 rate of $18: 3 n-6$, DGLA and AA in the total fatty acid than that in the wild strain

7 Overexpression of the endogenous $\omega 3$ gene in the wild strain and $\mathrm{S} 14(\Delta 5$

8 desaturation-defective mutant) led to higher production of EPA $(0.8 \mathrm{~g} / \mathrm{l}, 30 \%)$ as shown

9 in Fig. 2 and 20:4n-3 (1.8 g/l, 35\%), which usually comprise about $10 \%$ of the total 10 fatty acids in the wild strain and S14 cultivated at low temperatures $\left(<20^{\circ} \mathrm{C}\right)$.

11 Molecular breeding of $\omega 3$ gene-overexpressing transformants gave only high productivities of these n-3 C20 PUFAs. Overexpression of both the elongase PavElO (involved in the conversion of C20 to C22 PUFAs in marine microalga Pavlova sp.) and $\omega 3$ genes in the wild strain led to the formation of C22 PUFAs, n- 6 docosatetraenoic acid (22:4n-6) and n-3 docosapentaenoic acid (22:5n-3).

RNAi method with double strand RNA was applied to silencing gene expression in M. alpina $1 \mathrm{~S}-4$ (34). $\quad \Delta 12$ Gene-silenced strains accumulated n-9 octadecadienoic acid (18:2n-9), 20:2n-9, and MA, which are not detected in either the control strain or wild-type strain 1S-4. The fatty acid composition of these transformants was similar to that of $\Delta 12$ desaturation-defective mutants previously identified. Thus RNAi can be used to alter the types and relative amounts of fatty acids produced by commercial strains of this fungus as a simple method of silencing gene expression.

The RNAi of the $\Delta 12$ gene in MALCE1 activity-defective mutant M1 led to an accumulation of n-7 PUFAs and a decrease in n-4 PUFAs. This indicates that $n-4$ 
1 PUFAs are biosynthesized from n-7 PUFAs by $\Delta 12$ desaturation. In addition, the M1

2 transformant obtained on RNAi of the maelo gene accumulated n-4/n-7 PUFAs with a

3 decrease in n-6 PUFAs, which suggests that MAELO is involved in the elongation not

4 only of long chain saturated fatty acids such as 20:0 and 22:0 but also of 16:0. Such

5 molecular breeding of $M$. alpina strains should facilitate improvement of PUFA

6 productivity and elucidation of the functions of the enzymes involved in PUFA

7 biosynthesis.

8

\section{CONCLUSION}

The studies described above summarize our results related to PUFA production by oleaginous fungus $M$. alpina $1 \mathrm{~S}-4$ and the elucidation of fungal lipogenesis involved in PUFA biosynthesis. M. alpina $1 \mathrm{~S}-4$ and derivative mutants are potential sources of triacylglycerols rich in various PUFAs, including n-1, n-3, n-4, n-6, n-7, and n-9 PUFAs. It is possible to control the fatty acid profiles of fungal mutants and to regulate the flow of glucose or exogenous fatty acids to obtain a desired PUFA. The recent study on $M$. alpina and its mutants have been focused on molecular engineering of the enzyme genes involved in PUFA biosynthesis and pioneered the improvement of PUFA productivity. The breeding of mutants and transgenic strains may make it possible to produce desired PUFAs effectively. Further development of an efficient gene expression system for unique heterologous genes involved in such processes as lipid synthesis, PUFA synthesis, and lipid conversion, and construction of a homologous gene disruption system for $M$. alpina $1 \mathrm{~S}-4$ will enable elaboration of metabolic engineering for the production of various lipids with industrial interests. 


\section{ACKNOWLEDGEMENTS}

This work was partially supported by Grants-in Aid for Scientific Research (no.

622380051 to E.S. and no. 23248014 to J.O.), the Program for Promotion of Basic and

7 Applied Researches for Innovations in Bio-oriented Industry, and Advanced Low

8 Carbon Technology Research and Development Program.

References

1. Carlson, S. E., Werkman, S. H., Peeples, J. M., Cooke, R. J., and Tolley, E. A.: Arachidonic acid status correlates with first year growth in preterm infants, Proc. Natl. Acad. Sci. USA, 90, 1073-1077 (1993).

2. Gill, I. and Valivety, R.: Polyunsaturated fatty acids, part 1: Occurrence, biological (2001).

4. Mori, T. A., Beilin, L. J., Burke, V., Morris, J., and Ritchie, J.: Interactions between dietary fat, fish, and fish oils and their effects on platelet function in men at risk of cardiovascular disease, Arterioscler. Thromb. Vasc. Biol., 17, 279-286 (1997).

5. Qi, B., Fraser, T., Mugford, S., Dobson, G., Sayanova, O., Butler, J., Napier, J.
A., Stobart, A. K., and Lazarus,
C. M.: Production of very long chain 
polyunsaturated $\omega 3$ and $\omega 6$ fatty acids in plants. Nat. Biotechnol., 22, 739-745 (2004).

6. Ratledge, C.: Microbial lipids: Commercial realities or academic curiosities, pp. 1-15, in: Kyle, D. J. and Ratledge, C. (Eds), Industrial applications of single cell oils, AOCS Press, IL, (1992).

7. Ratledge, C.: Single cell oils - have they a biotechnological future?, Trends Biotechnol., 11, 278-284 (1993).

8. Shimizu, S., Kawashima, H., Shinmen, Y., Akimoto, K., and Yamada, H.:

9. Shinmen, Y., Shimizu, S., and Yamada, H.: Production of arachidonic acid by Mortierella fungi: selection of a potent producer and optimization of culture conditions for large-scale production, Appl. Microbiol. Biotechnol., 31, 11-16 (1989).

10. Yamada, H., Shimizu, S., and Shinmen, Y.: Production of arachidonic acid by Mortierell elongata 1S-5, Agric. Biol. Chem., 51, 785-790 (1987).

11. Jareonkitmongkol, S., Shimizu, S., and Yamada, H.: Fatty acid desaturation defective mutants of an arachidonic acid-producing fungus, Mortierella alpina 1S-4, J. Gen. Microbiol., 138, 997-1002 (1992).

12. Certik, M., Sakuradani, E., and Shimizu, S.: Desaturase-defective fungal mutants: useful tools for the regulation and overproduction of polyunsaturated fatty acids, Trends Biotechnol., 16, 500-505 (1998).

13. Jareonkitmongkol, S., Sakuradani, E., and Shimizu, S.: Isolation and characterization of a $\Delta 9$-desaturation-defective mutant of an arachidonic 
acid-producing fungus, Mortierella alpina 1S-4, J. Am. Oil Chem. Soc., 79, 1021-1026 (2002).

14. Sakuradani, E., Kamada, N., Hirano, Y., Nishihara, M., Kawashima, H., Akimoto, K., Higashiyama, K., Ogawa, J., and Shimizu, S.: Production of 5,8,11-cis-eicosatrienoic acid by a $\Delta 5$ and $\Delta 6$ desaturation activity-enhanced mutant derived from a $\Delta 12$ desaturation activity-defective mutant of Mortierella alpina 1S-4, Appl. Microbiol. Biotechnol., 60, 281-287 (2002).

15. Kamada, N., Kawashima, H., Sakuradani, E., Akimoto, K., Ogawa, J., and Shimizu, S.: Production of 8,11-cis-eicosadienoic acid by a $\Delta 5$ and $\Delta 12$ desaturase-defective mutant derived from the arachidonic acid producing fungus Mortierella alpina 1S-4, J. Am. Oil Chem. Soc. 76, 1269-1274 (1999)

16. Jareonkitmongkol, S., Shimizu, S., and Yamada, H.: Occurrence of two nonmethylene-interrupted fatty acids in a $\Delta 6$-desaturase-defective mutant of the fungus Mortierella alpina 1S-4, Biochim. Biophys. Acta, 1167, 137-141 (1993).

17. Jareonkitmongkol, S., Sakuradani, E., and Shimizu, S.: A novel $\Delta 5$-desaturase-defective mutant of Mortierella alpina $1 \mathrm{~S}-4$ and its dihomo- $\gamma$-linolenic acid productivity, Appl. Environ. Microbiol., 59, 4300-4304 (1993).

18. Sakuradani, E., Hirano, Y., Kamada, N., Nojiri, M., Ogawa, J., and Shimizu, S.: Improvement of arachidonic acid production by mutants with lowered w3-desaturation activity derived from Mortierela alpina 1S-4, Appl. Microbiol. Biotechnol., 66, 243-248 (2004).

19. Sakuradani, E., Kobayashi, M., and Shimizu, S.: $\Delta^{9}$-Fatty acid desaturase from arachidonic acid-producing fungus. Unique gene sequence and its heterologous 
expression in a fungus, Aspergillus, Eur. J. Biochem., 260, 208-216 (1999).

20. Abe, T., Sakuradani, E., Asano, T., Kanamaru, H., and Shimizu, S.: Functional characterization of $\Delta 9$ and $\omega 9$ desaturase genes in Mortierella alpina $1 \mathrm{~S}-4$ and its derivative mutants, Appl. Microbiol. Biotechnol., 70, 711-719 (2006).

21. Sakuradani, E. and Shimizu, S.: Gene cloning and functional analysis of a second $\Delta 6$-fatty acid desaturase from an arachidonic acid-producing Mortierella fungus, Biosci. Biotechnol. Biochem., 67, 704-711 (2003).

22. Sakuradani, E., Abe, T., Iguchi, K., and Shimizu, S.: A novel fungal w3-desaturase with wide substrate specificity from arachidonic acid-producing Mortierella alpina 1S-4, Appl. Microbiol. Biotechnol., 66, 648-654 (2005).

23. Sakuradani, E., Nojiri, M., Suzuki, H., and Shimizu, S.: Identification of a novel fatty acid elongase with a wide substrate specificity from arachidonic acid-producing fungus Mortierella alpina 1S-4, Appl. Microbiol. Biotechnol., 84, 709-716 (2009).

24. Parker-Barnes, J. M., Das, T, Bobik, E., Leonard, A. E., Thurmond, J. M., Chaung, L. T., Huang, Y. S., and Mukerji, P.: Identification and characterization of an enzyme involved in the elongation of n- 6 and n-3 polyunsaturated fatty acids, Proc. Natl. Acad. Sci. USA, 97, 8284-8289 (2000).

25. Sakuradani, E., Murata, S., Kanamaru, H., and Shimizu, S.: Functional analysis of a fatty acid elongase from arachidonic acid-producing Mortierella alpina 1S-4, Appl. Microbiol. Biotechnol., 81, 497-503 (2008).

26. Takeno, S., Sakuradani, E., Murata, S., Inohara-Ochiai, M., Kawashima, H., Ashikari, T., and Shimizu, S.: Cloning and sequencing of the ura3 and ura5 genes, and isolation and characterization of uracil auxotrophs of the fungus Mortierella 
alpina 1S-4, Biosci. Biotechnol. Biochem., 68, 277-285 (2004).

27. Takeno, S., Sakuradani, E., Murata, S., Inohara-Ochiai, M., Kawashima, H., Ashikari, T., and Shimizu, S.: Establishment of an overall transformation system for an oil-producing filamentous fungus, Mortierella alpina 1S-4, Appl. Microbiol. Biotechnol., 65, 419-425 (2004).

28. Ando, A., Sumida, Y., Negoro, H., Suroto, D. A., Ogawa, J., Sakuradani, E., and Shimizu, S.: Establishment of Agrobacterium tumefaciens-mediated transformation of an oleaginous fungus, Mortierella alpina 1S-4, and its application for eicosapentaenoic acid producer breeding, Appl. Environ. Microbiol., 75, 5529-5535 (2009).

29. Takeno, S., Sakuradani, E., Tomi, A., Inohara-Ochiai, M., Kawashima, H., and Shimizu, S.: Transformation of oil-producing fungus, Mortierella alpina 1S-4, using Zeocin, and application to arachidonic acid production, J. Biosci. Bioeng., 100, 617-622 (2005).

30. Ando, A., Sakuradani, E., Horinaka, K., Ogawa, J., and Shimizu, S.: Transformation of an oleaginous zygomycete Mortierella alpina 1S-4 with the carboxin resistance gene conferred by mutation of the iron-sulfur subunit of succinate dehydrogenase, Curr. Genet., 55, 349-356 (2009).

31. Ito, Y., Muraguchi, H., Seshime, Y., Oita, S., and Yanagi, S. O.: Flutolanil and carboxin resistance in Coprinus cinereus conferred by a mutation in the cytochrome $b 560$ subunit of succinate dehydrogenase complex (Complex II), Mol. Genet. Genomics, 272, 328-335 (2004).

32. Wynn, J. P. and Ratledge, C.: Evidence that the rate-limiting step for the biosynthesis of arachidonic acid in Mortierella alpina is at the level of the 18:3 to 
20:3 elongase, Microbiology, 146, 2325-2331 (2000).

2 33. Takeno, S., Sakuradani, E., Tomi, A., Inohara-Ochiai, M., Kawashima, H., Ashikari, T., and Shimizu, S.: Improvement of the fatty acid composition of an oil-producing filamentous fungus, Mortierella alpina 1S-4, through RNA interference with $\Delta 12$-desaturase gene expression, Appl. Environ. Microbiol., 71, 5124-5128 (2005).

7 34. Takeno, S., Sakuradani, E., Murata, S., Inohara-Ochiai, M., Kawashima, H., Ashikari, T., and Shimizu, S.: Molecular evidence that the rate-limiting step for the biosynthesis of arachidonic acid in Mortierella alpina is at the level of an elongase, Lipids, 40, 25-30 (2005). 


\section{$1 \quad$ Figure legends}

2

3 FIG. 1. Pathways for the Biosynthesis of PUFAs in M. alpina 1S-4 and its Mutants.

4 The n-3, n-6, and n-9 PUFAs are derived from 18:1n-9 (A), the

5 nonmethylene-interrupted PUFAs are detected in $\Delta 6$ desaturase-defective mutants (B),

6 and the n-1, n-4, and n-7 PUFAs are derived from 16:1n-7 (C). Black arrows show the

$7 \quad$ AA biosynthetic pathway in the parental strain, $M$. alpina 1 S-4. AA, arachidonic acid;

$8 \Delta \mathrm{N}, \Delta \mathrm{N}$ desaturase; DGLA, dihomo- $\gamma$-linolenic acid; EL, fatty acid elongase; EPA,

9 eicosapentaenoic acid; MA, Mead acid; $\omega 3, \omega 3$ desaturase.

10

11 FIG. 2. Conversion of n-6 PUFAs to n-3 PUFAs by $\omega 3$ desaturase from M. alpina

12 1S-4 (A) and chromatograms of fatty acid methyl esters prepared from fungal cells.

13 The strains were cultivated at $12^{\circ} \mathrm{C}$ for 11 days. 
(A)

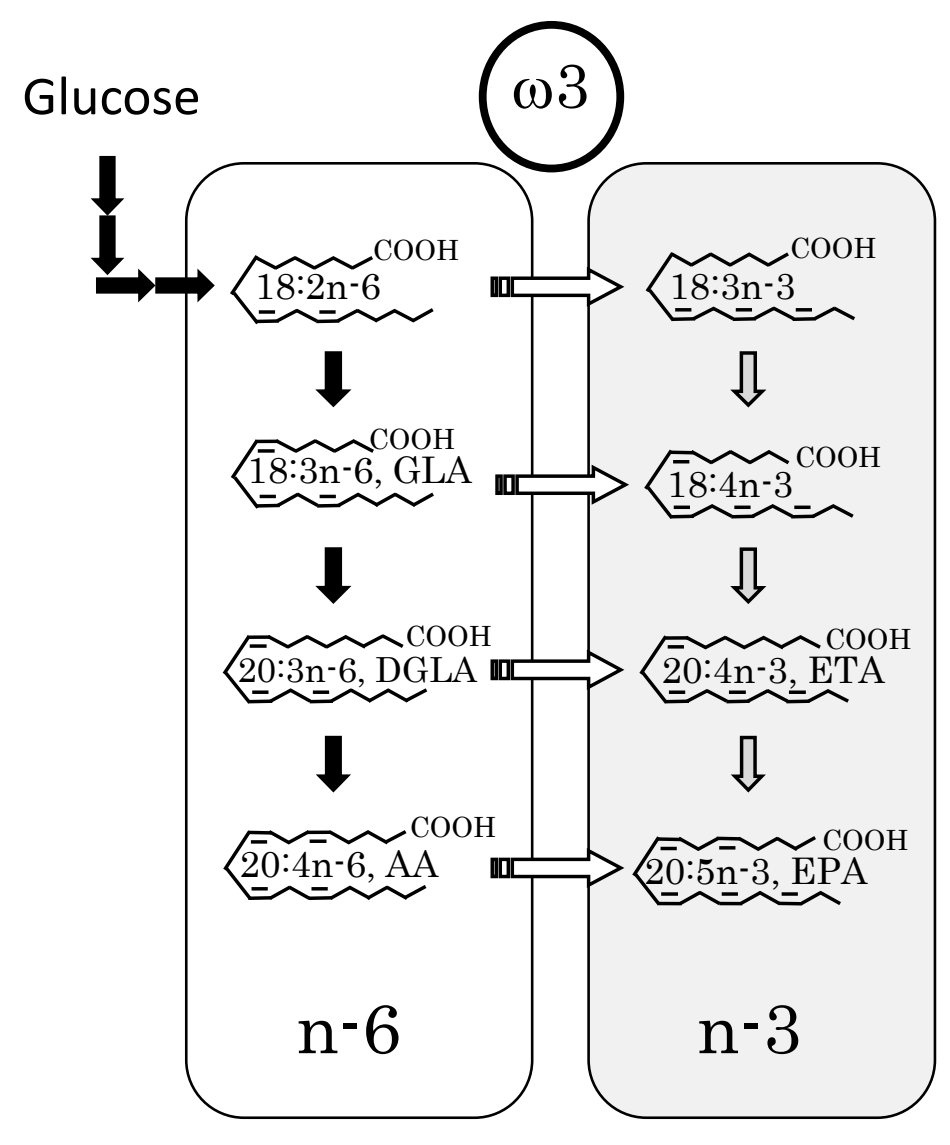

(B)

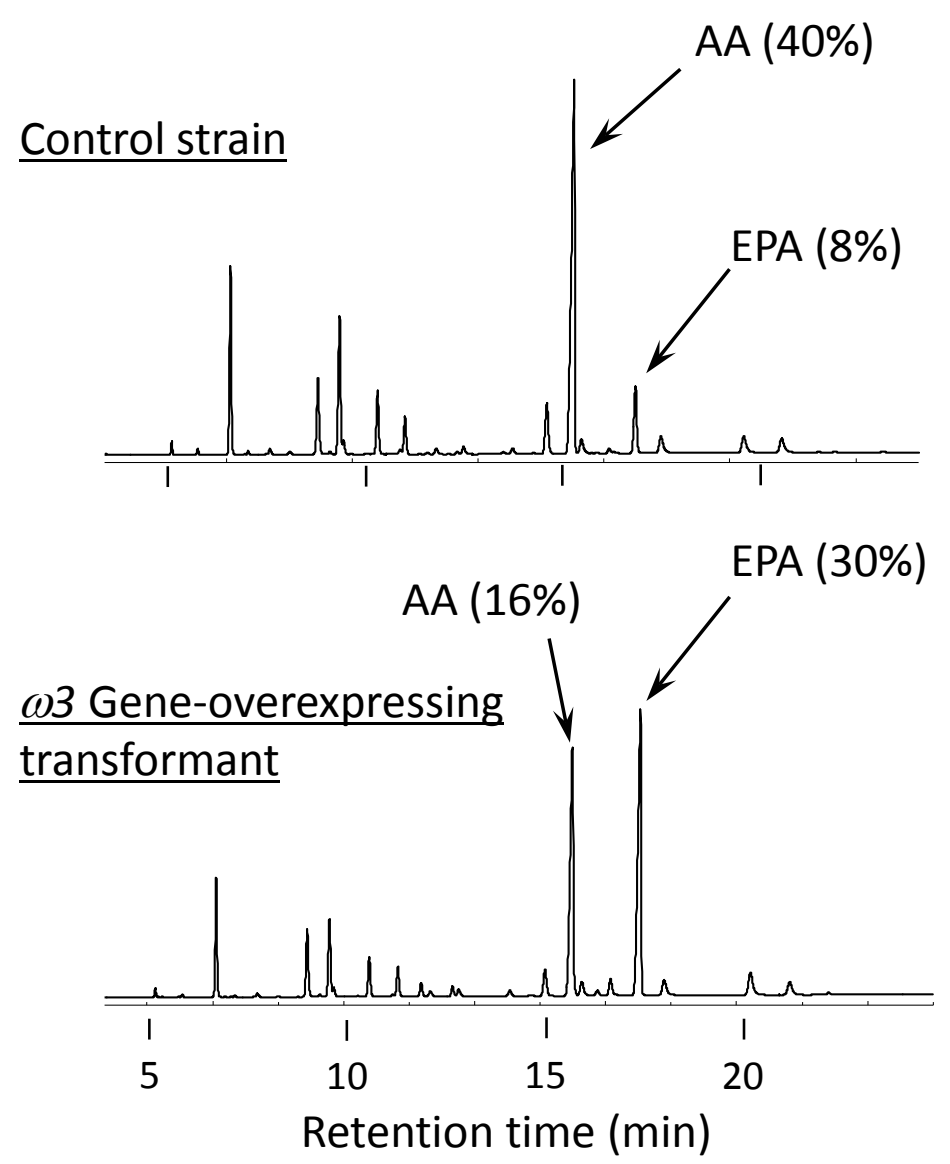


1 TABLE 1. Lipid productivities of Mortierella alpina 1S-4 mutants

\begin{tabular}{|c|c|c|c|c|c|}
\hline $\begin{array}{l}\text { Deficient } \\
\text { Enzyme }\end{array}$ & $\begin{array}{l}\text { Mutation } \\
\text { site }\end{array}$ & $\begin{array}{l}\text { Parent } \\
\text { strain }\end{array}$ & Mutant & Accumulation & Reference \\
\hline$\Delta 9$ & G265D & $1 \mathrm{~S}-4$ & $\mathrm{~T} 4$ & $18: 0(40 \%)$ & 13 \\
\hline$\Delta 12$ & $\mathrm{P} 166 \mathrm{~L}$ & $\begin{array}{l}\text { 1S-4, Mut48 } \\
\text { and M209-7b }\end{array}$ & JT-180 & $\begin{array}{l}\text { MA }(2.6 \mathrm{~g} / \mathrm{L}, 49 \% \text { of total fatty acids }) \\
\text { Enhanced activities of } \Delta 5 \text { and } \Delta 6 \text { desaturases }\end{array}$ & 14 \\
\hline$\Delta 12$ and $\Delta 5$ & $\begin{array}{l}\mathrm{P} 166 \mathrm{~L} \text { in }(\Delta 12) \\
\text { and W301Stop }(\Delta 5)\end{array}$ & 1S-4 and Mut48b & M226-9 & $20: 2 \mathrm{n}-9(2.2 \mathrm{~g} / \mathrm{L}, 37 \%)$ & 15 \\
\hline$\Delta 6$ & Incorrect splicing & $1 \mathrm{~S}-4$ & Mut49 & $20: 3 \mathrm{n}-6(\Delta 5)(0.48 \mathrm{~g} / \mathrm{L}, 7 \%)$ & 16 \\
\hline$\Delta 5$ & Incorrect splicing & $1 \mathrm{~S}-4$ & S14 & DGLA $(4.1 \mathrm{~g} / \mathrm{L}, 42 \%)$ and AA content $(<1 \%)$ & 17 \\
\hline$\omega 3$ & W232Stop & $1 \mathrm{~S}-4$ & Y11 & AA (1.5 g/L, 45\%) without n-3 PUFAs & 18 \\
\hline EL1 & H154Y andT185I & $1 \mathrm{~S}-4$ & M1 & $\begin{array}{l}16: 0(30 \%), 16: 1 n-7(8 \%) \\
\text { and } n-4 / n-7 \text { PUFAs }(30 \%)\end{array}$ & - \\
\hline N.D. ${ }^{a}$ & - & $1 \mathrm{~S}-4$ & KY1 & Diacylglycerol (30\% of total lipids) & - \\
\hline N.D. & - & $1 \mathrm{~S}-4$ & V6 & Lipid excretion (10-40\% of total lipids) & - \\
\hline
\end{tabular}

17 aN.D., not determined.

18 bMutants derived from M. alpina 1S-4. 
TABLE 2. Molecular Breeding of M. alpina 1S-4 and Its Mutants for PUFA Production

\begin{tabular}{|c|c|c|c|c|}
\hline Accumulated PUFA & $\operatorname{Host}^{\mathrm{a}}$ & Target gene ${ }^{b}$ & Method $^{\mathrm{c}}$ & Note \\
\hline $\mathrm{AA}$ & JT-180 & $\Delta 12$ & $\mathrm{OE}$ & $\begin{array}{l}\text { Higher AA production in JT-180 ( } 2.0 \mathrm{~g} / \mathrm{l} / 7 \text { days, } 39 \% \text { of total fatty acids) than wild } \\
\text { strain } 1 \mathrm{~S}-4 \text { (1.2 g/1/7 days, } 21 \%)\end{array}$ \\
\hline $\mathrm{AA}$ & $1 \mathrm{~S}-4$ & malce1 & $\mathrm{OE}$ & $\begin{array}{l}\text { Higher accumulation of AA in a transformant }(0.76 \mathrm{~g} / 1 / 6 \text { days, } 34 \%) \text { than wild strain } \\
\text { 1S-4 (0.68 g/1/6 days, } 28 \%)\end{array}$ \\
\hline AA & $1 \mathrm{~S}-4$ & glelo & $\mathrm{OE}$ & $\begin{array}{l}\text { Higher AA production in a transformant (3.6 g/l/10 days, } 28 \%) \text { than wild strain } 1 \mathrm{~S}-4 \\
(1.9 \mathrm{~g} / \mathrm{l} / 10 \text { days, } 19 \%)\end{array}$ \\
\hline AA & $1 \mathrm{~S}-4$ & Pav $\Delta 5$ & $\mathrm{OE}$ & $\begin{array}{l}\text { A higher rate of AA }(40 \%) \text { and a lower rate of DGLA }(1 \%) \text { in a transformant than } \\
\text { rates of AA }(35 \%) \text { and DGLA }(4 \%) \text { in wild strain } 1 \text { S-4 }\end{array}$ \\
\hline AA & $1 \mathrm{~S}-4$ & Ost $\Delta 6$ & $\mathrm{OE}$ & A higher rate of AA $(44 \%)$ in a transformant than $(35 \%)$ that in wild strain $1 \mathrm{~S}-4$ \\
\hline EPA & $1 \mathrm{~S}-4$ & $\omega 3$ & $\mathrm{OE}$ & High EPA production (0.8 g/1/11 days, $30 \%)$ \\
\hline $20: 4 n-3$ & S14 & $\omega 3$ & $\mathrm{OE}$ & High $20: 4 \mathrm{n}-3$ production (1.8 g/1/11 days, $35 \%)$ \\
\hline $22: 4 n-6,22: 5 n-3$ & $1 \mathrm{~S}-4$ & PavELO, $\omega 3$ & $\mathrm{OE}$ & Detection of small amounts of $22: 4 n-6$ and $22: 5 n-3$ in wild strain $1 S-4$ \\
\hline MA & $1 \mathrm{~S}-4$ & $\Delta 12$ & $\mathrm{Ri}$ & Accumulation of n-9 PUFAs \\
\hline $20: 3 n-6(\Delta 5), 20: 2 n-6$ & $1 \mathrm{~S}-4$ & $\Delta 6$ & $\mathrm{Ri}$ & Accumulation of $20: 3 n-6(\Delta 5)$ and $20: 2 n-6$ \\
\hline $16: 0,16: 1 n-7$ & $1 \mathrm{~S}-4$ & malce1 & $\mathrm{Ri}$ & Accumulation of $16: 0$ and $16: 1 n-7$ \\
\hline n-4/n-7 PUFA & M1 & maelo & $\mathrm{Ri}$ & Accumulation of n-4/n-7 PUFAs and decrease of n-6 PUFAs \\
\hline n-7 PUFA & M1 & $\Delta 12$ & $\mathrm{Ri}$ & Accumulation of n-7 PUFAs and decrease of n-4 PUFAs \\
\hline 18:0, PUFA & $1 \mathrm{~S}-4$ & maelo & $\mathrm{Ri}$ & $\begin{array}{l}\text { No accumulation of } 22: 0 \text { and } 24: 0 \text {, and small increases in 18:0 and the following } n-6 \\
\text { PUFAs }\end{array}$ \\
\hline
\end{tabular}

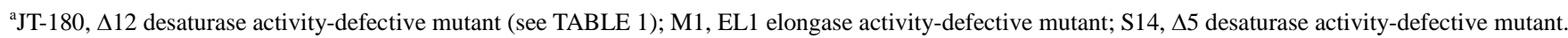

${ }^{\mathrm{b}}$ The genes, except for Pav 45 , Ost $\triangle 6$, and PavELO, were all derived from M. alpina $1 \mathrm{~S}-4$.

${ }^{\mathrm{c} O E}$, overexpression; Ri, RNAi. 